\title{
ON PAIN AND THE PRIVATION THEORY OF EVIL
}

\section{IRIT SAMET}

\author{
King's College London
}

\begin{abstract}
The paper argues that pain is not a good counter-example to the privation theory of evil. Objectors to the privation thesis see pain as too real to be accounted for in privative terms. However, the properties for which pain is intuitively thought of as real, i.e. its localised nature, intensity, and quality (prickly, throbbing, etc.) are features of the senso-somatic aspect of pain. This is a problem for the objectors because, as findings of modern science clearly demonstrate, the senso-somatic aspect of pain is neurologically and clinically separate from the emotional-psychological aspect of suffering. The intuition that what seems so real in pain is also the source of pain's negative value thus falls apart. As far as the affective aspect of pain, i.e. 'painfulness' is concerned, it cannot refute the privation thesis either. For even if this is indeed the source of pain's badness, the affective aspect is best accounted for in privative terms of loss and negation. The same holds for the effect of pain on the aching person.
\end{abstract}

\section{INTRODUCTION}

'Just as there is no target set up for misses, so there is no nature of evil in the universe either'. (Epictetus, Encheiridion 27)

Philosophers since Plato have been making a striking claim about evil: evil, they said, is essentially devoid of being, an absence of good. This seemingly absurd statement became the standard conclusion of rationalistic investigations into the ontology of evil. The difference between the theories lay mainly in the way they arrived at the conclusion that evil is privation, and in the metaphysical framework they worked 
with; about the ontological last line they were unanimous: evil has no independent being.

The concept of evil as privation implies that like silence and darkness, evil does not have an independent content, or definition, or existence - for all this it is dependent on the good. But in difference with the 'absence of sound' which is silence, and the 'non presence of light' which is darkness, 'badness' is a lack of what ought to be. It is, in other words, a privation of the normative. Such a view of evil is an inevitable result of the Platonic and Aristotelian metaphysics in which goodness is identified with being. But the privation thesis has also become a cornerstone in the philosophical engagement with the question of theodicy.

Very early on, we find Augustine using the idea of 'evil as privation' to conceptually isolate what we experience as evil from the idea of God, both as the Creator of all things and as the One who sustains them through constant affirmation. If evil is not a substance, it was not created, and the Manichean urge to stipulate a competitive evil deity is nipped in the bud. But an instinctual objection immediately arises: if 'being' is identified with 'goodness', why do we keep on coming across what seem like clearly bad states of affairs? In his answer to the objectors Augustine develops what has become known as 'the universality thesis': every thing is good inasmuch as it has being, and bad to the extent to which it lacks being; in his words:

'what is evil[?]... nothing else than corruption, either of the measure, or the form, or the order, that belong to nature. Nature therefore which has been corrupted, is called evil;... but even when corrupt, so far as it is nature it is good, so far as it is corrupted it is evil.'.

This paper does not offer a defence of the privation thesis. Instead, I propose to examine the objectors' favourite concrete counter-example: pain. Isn't it obvious, they ask, that pain is both evil and real? Conceptually, pain is situated in a unique crossroad between the discourses of natural science and morality, a fact which turns the ontological analysis into a particularly tricky business. But I shall argue that if we carefully analyse

\footnotetext{
${ }^{1}$ Augustine, 'On the Nature of the Good' in P. Schaff, ed. A Select Library of Nicene and post-Nicene Fathers of the Christian Church: A New Series (Oxford, Buffalo: Parker \& Co., The Christian literature company, 1886) chapter 17. For a modern Platonic concept of a supreme transcendent good, and the asymmetrical relationship between good and evil that it implies see R.M. Adams, Finite and Infinite Goods: A Framework for Ethics (New York: Oxford University Press, 1999), esp. pp. 102-4.
} 
the way in which pain is said to be bad in light of the findings of modern science, we will find that we can apply Augustine's 'universality thesis' to it: in as much as pain is real it is not bad, and in as much as pain is bad it is best accounted for in privative terms of negation.

\section{THE PRIVATION THESIS}

The relationship between 'bad' and 'good' can be depicted in one of three ways: contrast, negation, or privation. If the relationship is one of contrast, everything is either bad or good. Contrasting properties are distinguished from contrary properties $\mathrm{X}$ and $\mathrm{Y}$, in that $\mathrm{X}$ and $\mathrm{Y}$ cannot be properties of the same item, but it is not the case that each item which can in principle be $\mathrm{X}$ or $\mathrm{Y}$ will indeed be either $\mathrm{X}$ or $\mathrm{Y}$. Thus 'being red all over' and 'being blue all over' cannot be properties of the same item, but a coloured item need not be either blue or red; it can be yellow. If taken as contrasts, however, the properties 'bad' and 'good' are symmetrical and exhaustive; that is, in the relevant categories, items are either good or bad, $[$ good $]=[\neg$ bad $]$ and $[\neg$ good $]=[$ bad $]$.

If bad is a negation of good, this symmetry between the properties breaks down, as the good is not a negation of the bad. Here, badness is seen as a mere lack of goodness, parallel to the way in which darkness is defined as an absence of light. It is asymmetrical because light is not understood as a lack of darkness. As the example of darkness and light demonstrates, it is not the case that each object or state of affairs necessarily exhibits one of the two negating properties. But if [being illuminated] can in principle apply to an object, then either it or its negation must obtain (unlike asking whether my craving for ice cream is illuminated or dark, which is a categorical mistake). In difference to contrasts, though, $[\neg$ bad $] \neq$ [good], even though [bad $]=[\neg$ good $]$.

As a result, if the relationship between good and evil are put in terms of privation, then the relationship between good and bad is a-symmetrical. The good has precedence over the bad, because bad is a mere privation of good. To say of a state of affairs that it is bad, is to say that something which ought to have been there is lacking. Unlike silence or inactivity, badness is set against the normative; hence the relation is that of privation (rather than mere contrast or negation). Thus, anosmia is a privation of the sense of smell, and stupidity the absence of wisdom, but that is because, ideally, a person would possess 
both wisdom and a sense of smell. ${ }^{2}$ From an ontological point of view the bad will therefore be accounted for as some shortage/loss/lack of good that ought to exist. From an epistemological point of view, it will be impossible to understand the bad before we know the good.

It has been argued by many that all the elaborate theoretical edifice of the privation thesis crumbles in the face of one all-familiar experience: pain. Indeed, when asked about the intuitive appeal of the metaphysics of evil as privation, many would mention 'pain' as the first counterexample that comes to mind. ${ }^{3}$ For there is something in the quality of pain that makes it look both obviously evil and undoubtedly real. The strong sense of reality most likely comes from the way in which pain is embedded in the body. Pain can be throbbing, prickling or burning; like a physical object, it has a location in the body, measurable intensity, and time - all so different from the hole in the bagel.

A number of writers tried to tackle the challenge of pain by showing that it is a privation of a specific X: some suggest that $\mathrm{X}$ is 'pleasure, others that it is 'well-being', 'health' or 'normal functioning. None of these accounts is really satisfactory. ${ }^{4}$ But not all is lost for the privation theory. If pain is to prove that evil can be accounted for independently of the good, it must first be defined more clearly; and that is a surprisingly tricky task. Perhaps the simplest definition of pain would describe it as a 'sensation that hurts'. This crude definition already reveals a baffling duality between a somatic aspect and a mental aspect of 'how it feels'. Recent findings on the way it is processed and experienced demonstrate that this duality in pain is far more complicated than in other sensations

\footnotetext{
${ }^{2}$ Here is how Aquinas puts it: '[E]vil imports the absence of good. But not every absence of good is evil. For absence of good can be taken in a privative and in a negative sense. Absence of good, taken negatively, is not evil; otherwise, it would follow that what does not exist is evil, and also that everything would be evil, through not having the good belonging to something else; for instance, a man would be evil who had not the swiftness of the roe, or the strength of a lion. But the absence of good, taken in a privative sense, is an evil; as, for instance, the privation of sight is called blindness' (T. Aquinas, Summa Theologiae (London: Burns, Oates, and Washbourne, 1912-36), I q.48, Argument 3, Answer).

3 See for example T. Calder, 'Is the privation theory of evil dead?', American Philosophical Quarterly, 44 (2007), 371, p. 373.

${ }^{4}$ As persuasively shown by Ibid., 'The absence of pleasure, in itself, is not pain, although it may be the cause of pain' (p.373) and G.S. Kane, 'Evil and Privation', Int J Phil Rel, 11 (1980), 43, 'pain seems clearly to be more than merely the absence of its contrary opposite... when pain occurs in the body, there is something new and different in a person's experience which is not present when the body has simply lost feeling' (p. 49).
} 
such as taste and sight. This peculiar relationship between the sensational and the emotive aspects of pain must be taken into account when we try to establish the source of pain's negative value. But once we have done that, we will see that the badness of pain is most successfully represented in negative terms of privation and loss.

\section{THE SOMATIC ASPECT}

Let us start then with the somatic element. By now, neuroscientists are pretty clear about the neurophysiologic aspects of pain processing. ${ }^{5}$ Some 100 years after it was offered by Head and Holmes, researchers still hold to the basic idea that our pain sensory system is comprised of two subsystems: one is the sensory discriminative system, which works out the noxious stimuli's location, intensity, duration and kind (prickling, throbbing, burning etc.); the other is the 'affective-motivational' system which supports the unpleasantness aspect of the pain sensation. ${ }^{6}$

The two subsystems are served by different neurons (A- $\delta$ fibres, and C fibres respectively), with the effect that the sensory system transmits the first fast pain, and the affective system kicks in later and continues to fire even after the nerve endings are no longer stimulated. Although the $A-\delta$ fibres and $C$ fibres pathways do interact (more than, say, the colour and distance pathways in the vision system), they eventually project into different areas in the brain: the fast pain information is processed by the somatosensory cortex which then produces data on the intensity, location and nature of pain, and the slow pain information arrives at the frontal lobe which handles the emotional reaction of hurt. ${ }^{7}$

The involvement of two quasi separate subsystems accounts for one of the most fascinating and baffling features of pain processing: the possibility of dissociation between the qualitative aspects of the experience (aching), and its quantitative ones (duration, intensity, etc.). We have, for example, a vast body of empirical datum which demonstrates how perception of the intensity of pain is in fact independent of its unpleasantness. Thus, patients who took morphine or suffered lesions to

${ }^{5}$ K. Sufka, 'Sensations and Pain Processes', Philosophical Psychology, 13 (2000), 299, p. 302.

${ }^{6}$ Ibid., p. 302.

7 The structure is of course much more complicated than this embarrassingly simplistic description. For a more detailed, but user-friendly description, see for example: S. Horn and M. Munafò, Pain: Theory, Research, and Intervention (Buckingham: Health Psychology, Open University Press, 1997), chapter 2 and the sources cited there. 
certain pain-processing areas in the brain can localise their pain, register its intensity and note its kind (probing, burning etc.), and all that without experiencing the slightest anguish.

More unfortunate are the Parkinson's patients who can often feel the agony of pain without being able to localise it in their body. ${ }^{8}$ In a laboratory experiment, researchers managed to use hypnosis in order to change the subject's perception of the obnoxiousness of hot water, without thereby changing the subject's estimation of the intensity of the heat. PET scans showed that such changes in the unpleasantness were accompanied by activity in the anterior cingulated cortex- the area that is responsible for the processing of the 'painful' feeling, while the other pain-processing areas remained quiet. ${ }^{9}$ With other sensations such division is hard even to conceptualise: it makes no sense to say that one perceives the tonal difference between different notes, and yet fails to experience the hearing of these notes. It is only with pain that a distinction between affect and sensation is possible. ${ }^{10}$

Let us go back to the privation thesis. It seems that the embodiment of pain (e.g. its localised nature or the physical way in which we describe its qualities) is the main reason why it is immediately thought of as a bad aspect of the world which is too real to be defined in privative terms. But now we see that with pain the analytical distinction between the sensory-detecting component and the psychological-emotional component of hurting is not merely conceptual - it is wired into the experience itself. And the 'realness' of pain, i.e. its locality and intensity, is obviously anchored in the somatic aspect. This is a big problem for the intuition that pain is a powerful counter-example to the privation thesis. Because as far as the somatic aspect is concerned, pain is a good thing, as its contribution to the ability to detect harm to body tissue is essential for the wellbeing of animals. Statistics shows that congenital or acquired

${ }^{8}$ See the sources cited in V. Grayhardcastle, 'When pain is not', The Journal of Philosophy 94 (1997), 381, pp. 392-3.

${ }^{9}$ Pierre Rainville, Gary H. Duncan, Donald D. Price, Benoît Carrier, M. Catherine Bushnell, 'Pain Affect Encoded in Human Anterior Cingulate But Not Somatosensory Cortex', Science 277 (1997), pp. 968 - 971.

${ }^{10}$ Note that this distinction is different from the distinction which philosophers make between 'Qualia' and sense data - what we called 'quantitative' aspects of pain comprise of both sense data and qualia; for example, the question whether a stimulus to nerve ends is prickling or burning can be answered from a purely objective point of view of the stimuli, but also from the subjective perspective of 'how does it feel'. 
conditions which inhibit the sensation of pain (analgesia) are likely to shorten the patients' lives. ${ }^{11}$ The sense of pain functions both as an alarm and as a powerful motivation to care for the body. ${ }^{12}$ It is therefore clear that the purely sensory element of pain cannot be the source of pain's evil. ${ }^{13}$ In as much as it has any normative significance, it is intrinsically good. The negative value of pain must be rooted in a different aspect of the phenomenon.

\section{THE AFFECTIVE ASPECT}

If the somatic aspect of pain is axiologically neutral (or positive), the best candidate for being the source of pain's negative value is the affective element, i.e. hurting or painfulness. Accounting for pain's badness in this way largely waters down the power of the original intuition that prompted pain as a prime counter-example to the privation thesis. For hurt cannot be located in the brain in the same fashion as pain can be located in a finger. Even the most ardent neuroscientists will be careful to stress that the great amount of data we have about the relation between (mainly cortical) activity in the brain and subjective unpleasantness still cannot prove that the psychological reaction to noxious stimuli can be reduced to the firing of neurons in the brain. ${ }^{14}$ At the most, one can argue that the feeling of suffering supervenes on the activity in the relevant brain areas. But still, isn't the feeling of painfulness really there in your psyche?

${ }^{11}$ Even if such patients can be taught to pay careful attention to possible lesions on their skin, damage to internal body parts can be left unattended until it is too late. See for example John J. Haddad, 'On the Enigma of Pain and Hyperalgesia: A Molecular Perspective', Biochemical and Biophysical Research Communications, 353 (2007), pp. 217-224.

${ }^{12}$ The way in which soldiers and athletes can sometimes function normally following a grievous injury without feeling any pain for a long time, does not show that we could do without pain; far from it. The reports on postponed pain reaction only attest to the sophistication of the pain mechanism. In times of extreme stress, when animals must fight or flee an enemy, they are better off if they can do so without the overwhelming effect of pain, even if that means that the damage to the limb is increased due to delayed care. When the injured eventually finds sanctuary, be it in the first-aid post or the showers, the sense of pain will kick in forcefully. Grayhardcastle, p. 407.

${ }^{13} \mathrm{R}$. Melzack, one of the fathers of the revolutionary 'gate theory' of pain, takes a similar stance: 'If... noxious input fails to evoke negative effect and aversive drive... the experience cannot be called pain.' R. Melzack, The Puzzle of Pain (New York: Basic Books, 1973).

${ }^{14}$ K. Sufka, 'Sensations and Pain Processes', Philosophical Psychology, 13 (2000), 299, p. 307. 
Maybe. But the anti-privationists will also have to show why the badness of suffering does not lend itself to analysis in terms of privation. They will find it hard to do so. There are two main ways of analysing the normative significance of suffering, I will call them the 'naturalist' and the 'Kantian'. Significantly, both are expounded by their proponent in basically negative terms. The naturalist maintains that pain has a very unique role in the axiological discourse, as it is the point where the natural and the normative unite. Thus, according to Nagel, 'pains ... provide at least agent-relative reasons for ... avoidance, reasons that can be affirmed from an objective standpoint.' ${ }^{15}$ The normative meaning of pain lies in the way it can in itself give us a reason to stop it (by taking pain killers, act to release the POW, make a donation to Oxfam, etc.).

The Kantian must disagree: for her, the normative is always built on consciousness, and therefore pain, like any natural phenomena, cannot by itself be normative. Being in pain means having a very strong inclination to put an end to the present state of affairs, and its normative significance lies in 'your perception that you have a reason to change your condition. ${ }^{16}$ The painfulness of pain is nature's way of ensuring that we are strongly inclined to take care of ourselves, but it is the harm (to the self or to others) and not the painfulness which gives us a reason to act. In arguing that pain has a negative value because of the way we want to break away from the sensation, one is not at all committed to a subjective view of pain (i.e., to the view that the normative value of pain is in the mind and not in the world). As Korsgaard explains, the reasons which pain gives rise to are derived from our shared humanity, and therefore they apply to your pain as much as to mine. ${ }^{17}$

For our purposes, it is important to note how despite deep differences in respect to the function of pain in the axiological scheme, both the naturalist and the Kantian account for the evil of pain in privative terms: painfulness is conceived as a condition which one wants to put an end to, as a space to escape from, a sensation whose significance lies in its undesirability. It seems therefore that if pain is defined as a hurting bodily

${ }^{15}$ T. Nagel, The View From Nowhere (New York: Oxford University Press, 1986), pp. 156-8.

${ }^{16}$ C.M. Korsgaard, The Sources of Normativity (Cambridge: Cambridge University Press, 1996), p. 146, therefore, pain which one does not want to avoid is not bad (p. 154); A. Swenson, 'Pain's Evils', Utilitas, 21 (2009), 197, p. 207.

${ }^{17}$ See also E. Scarry, The Body in Pain: The Making and Unmaking of the World (New York: Oxford University Press, 1985), who talks of pain as lacking a content of its own, a 'sheer aversiveness' (p. 52). 
sensation the intuitive appeal of the counter-example is largely lost: the somatic aspect which makes it so irresistibly real cannot be the locus of pain's badness, and the way in which the affective aspect confers negative value on pain is best accounted for in privative terms of breaking away and ending.

\section{PAIN AS ACCESS}

But maybe the essence of pain can be described in a different way that more successfully grounds the original intuition about the realness of pain? In his masterful study of the ontology of evil, Adi Ophir argues that pain is not an independent bodily sensation, but rather an overload of other sensations. Thus, he suggests that pain is 'a sensation whose amplified presence overflows so as to make it unbearable, while the person who is present (to it) avoids, or is prevented from, discarding it. ${ }^{18}$ The definition alludes to the way in which sensations can turn into pain when they become excessive, i.e. over present. Thus, for example, too much touch can be experienced as a blow, harassment or 'Chinese torture.' Moreover, it is in the nature of these excesses that their presence to the sufferer is further augmented by her inability to make them disappear. ${ }^{19}$ If pain is indeed an excess of $\mathrm{X}$ ( $\mathrm{x}=$ =sensation), then it is essentially an overload of reality and the exact opposite of privation.

Alas, his innovative account of pain as over-presence of other sensations does not save Ophir from slipping into the same trap as the more conventional definition. For his explanation of the badness of pain resorts to privative terminology of passivity and helplessness: 'inability to get away from an overflowing sensation' (6.000); 'a desire to break off (6.030); In other places Ophir offers an explicitly privative explanation of suffering as appearing as 'the gap between the unbearable [i.e., the sensation] and the impossible [i.e., the act needed in order to make it tolerable]' (6.400). It seems that when it comes to describing the badness of pain, the privation terms are unavoidable. Sensation in itself is axiologically neutral, and having more of it cannot change this. The essence of its transformation into value-laden phenomena, i.e., when pain becomes suffering, is best expressed in negative terms as the victim's inability to end it.

\footnotetext{
${ }^{18}$ A. Ophir, Speaking Evil: Towards an Ontology of Morals (Tel-Aviv: Am Oved \& Van Leer institute, 2000), Sec. 6.0.

${ }^{19}$ Ibid. 6.010.
} 
But perhaps the account of pain's badness as 'inability to stop or escape it' is not really a definition in negative terms? In his 'Time and the Other' Emanuel Levinas argues that ' $[\mathrm{P}]$ hysical suffering... in all its degrees entails the impossibility of detaching oneself from the instance of existence. It is the very irremissibility of being. ${ }^{20}$ Pain is sui generis, he says, in that it is defined by the impossibility of fleeing or avoiding the situation, but in that it exemplifies the 'impossibility of nothingness' (p. 40). If what makes pain bad is the way you want it not to exist but cannot do so (for otherwise you wouldn't be in pain), it is a negation of the possibility not to be ([pain] $=\neg \neg$ [presence]).

Yet, the logic of the paradox here is flawed: [me wanting to end the state of pain] and [me not being able to do so] are two separate states that cannot negate each other, and my perceptions of these two states are also analytically separate. Think of a young child who has not yet developed an insight of himself as a person; he can still experience pain as something that he craves would stop, even while he cannot think of himself as being unable to stop it.

A similar view seems to underlie Jean Améry's observation that 'nowhere else in the world did reality have as much effective power as in the camp, nowhere else was reality so real. ${ }^{21}$ In the insightful and moving report of his experience in the Gestapo's torture chambers, Améry claims that physical pain has an exceptional power to immerse the victim in reality: 'Whoever is overcome by pain through torture experiences his body as never before. In self negation, his flesh becomes a total reality... the tortured person is only a body, and nothing besides that' (p. 33). But if we look carefully at what Améry has in mind when he talks about 'reality' here, we will see that he is using the term in a very different sense from that used by the privation thesis.

The question that interests Améry is not the metaphysics of being (Heidegger is mockingly referred to as 'the magus from the Alemannic regions'), but rather the effect which extreme conditions of misery have over the intellect. He finds that the severe pain of torture, or the prolonged anguish of the inmates of concentration camps, have a devastating effect on the power of the intellect to raise us above mere physical existence: 'in no other place did the attempt to transcend it [i.e. reality] prove so

\footnotetext{
${ }^{20}$ E. Lévinas and S. Hand, The Levinas Reader (Oxford: Blackwell, 1989), p. 39.

${ }^{21}$ J. Améry, At The Mind's Limits: Contemplations by a Survivor on Auschwitz and Its Realities (Bloomington: Indiana University Press, 1980), p. 19.
} 
hopeless and so shoddy' (p. 19). The 'reality' he talks about is the physical, embodied existence to which the subject is locked by pain.

This is of course a much more limited sense of 'reality' than the abstract 'being' which the metaphysics of evil refers to. Moreover, Améry's depiction of the evil particular to excruciating pain is patently privative: the evil of extreme anguish, he says, lies in the way it prevents the sufferer from realising his humanity. Like a horrific mirror image of his torturer, the victim is unable to elevate himself to the loftier forms of existence where his humanity can be expressed in full. ${ }^{22}$ And that takes us to another way in which pain can be thought to pose a serious problem for the privation theory, namely, its effect.

\section{THE EFFECT}

A person, or a limb, in pain is dramatically different from its healthy form. When strong enough, pain can change the sufferer beyond recognition, as it takes hold of her entire body and soul. How can the driving force behind such a momentous change be devoid of being? In the background lurks a more general question about the nature of evil. In the opening question of his treatise On Evil Aquinas asks 'whether evil is something.' The intuition that evil is indeed real is put in a straightforward manner in the first objection: 'Everything created is something. But evil is something created ... therefore evil is something. ${ }^{23}$ Evil, the objection goes on, even has its own proper activity - it corrupts. And corruption is a change, a movement from one state to another, a transformation that is as natural as creation. Can it be that such a potent agent is devoid of reality?

Yes, says Aquinas. He begins by drawing a basic distinction between the notions of 'evil simply' and 'evil in some respect.' When we say of $\mathrm{X}$ that it is bad, what we really say is that some good aspect that pertains to it by its nature is missing. So ' $\mathrm{X}$ is bad' can mean ' $\mathrm{X}$ is bad in some way'; what it cannot mean is ' $\mathrm{X}$ is bad simpliciter'. The notion of evil simpliciter can never be an attribute of $\mathrm{X}$ because at the moment that $\mathrm{X}$ crosses the line from 'having some bad aspects' to 'being wholly bad' it disintegrates

${ }^{22}$ For a privative account of torture as a violation of the sacred see Adams, pp. 107114. A similar theme of the biblical transgression as a violation of the bond between God and man is identified by P. Ricœur, The Symbolism of Evil (Boston: Beacon paperback Ariadne, Beacon Press, 1969), pp. 50-54.

${ }^{23}$ Aquinas Q1, A1, obj. 1. 
and ceases to be $\mathrm{X} .{ }^{24}$ Thus, a bad washing machine can leave some stains on garments, fail to drain the water properly, leave clothes with too many creases, etc. But if the machine does not do any cleaning because it does not take in water, or has no receptacle for laundry or container for soap, it is not a 'bad washing machine'; rather, it is not a washing machine at all. Sometimes we have a word for the item in the new stage, such as 'wreck' or 'corpse', for example, but not always. Either way, when the bad aspects of an item take over completely, it ceases to exist as that item. This works for pain as well. Taken simpliciter, say for the sake of laboratory experiment on pain killers, a good pain is that which is really hurting; rather more chilling examples would be the pains that the torturer or the sadist seek to induce - when pain is sought for its own sake, the more anguish the better.

But the reason why pain is seen as a potential counter example to the privation theory is not as per se but rather as relational to the limb or the body it is 'in'. Can we say that as the agent of the change that is brought about on the aching body, a movement from one state to another, pain must be seen as an independent being? No, says Aquinas:

[T] hat which is evil, if it is evil simply, i.e. in itself, so corrupts or actively and effectively makes the thing corrupt not by acting but by dis-acting, i.e. by failing to act by reason of a deficiency of active power, as for example defective seed generates defectively and produces a monstrosity, which is a corruption of the natural order. ${ }^{25}$

If we look at what happens with $\mathrm{Y}$ which has gone through a process of corruption, we see that it is actually a loss of good states. Ontologically, the change brought about by evil is akin to a ball rolling down the hill, in that there is no need for an active agent to push the ball. Epistemologically, the change can only be understood on the background of the proper state

${ }^{24}$ In Augustine's words: 'No nature, therefore, as far as it is nature, is evil; but to each nature there is no evil except to be diminished in respect of good. But if by being diminished it should be consumed so that there is no good, no nature would be left.' St. Augustine, 'On the Nature of Good' in P. Schaff, ed. Nicene and Post-Nicene Fathers (Buffalo, NY: Christian Literature Publishing Co., 1887), chapter 17.

${ }^{25} \mathrm{Q} 1, \mathrm{~A} 1, \mathrm{Rep} .8$. For the way his ontology of privation informs his analysis of moral wrongdoing and vice see J. Aertsen, Medieval Philosophy and the Transcendentals: The Case of Thomas Aquinas (Bd. 52, Brill, Leiden: Studien und Texte zur Geistesgeschichte des Mittelalters, 1996), pp. 319-34, and N. Kretzman and E. Stump, 'Being and Goodness' in S. MacDonald, ed. Being and Goodness: The Concept of the Good in Metaphysics and Philosophical Theology (Ithaca: Cornell University Press, 1991), pp. 103-6. 
of the affected Y. As the change consists only of a loss of this proprietary, and has no independent content.

We tend indeed to talk about an $\mathrm{X}$ (say risky mortgage practices), as 'bad' when it induces a process of deterioration in another entity (the credit market). But the corruption itself always comes down to a failure to act or function well. An under-regulated market gradually ceases to function according to its proper action, and the process is best described as a (gradual or acute) diminution in the goods which it purportedly holds for the players. And this process cannot be accounted for without relying on the goods which a fully-functioning free market is supposed to produce.

The same holds for pain. If we try to analyse physical pain from the point of view of the effect it has over the victim, we see that far from being a counterexample to the privation thesis, it is actually a powerful expression of the rationalist tenets on which the thesis is based. This is because what is lost to those in severe pain is the logos. In her masterful 'The Body in Pain', Elaine Scarry offers a deep and systematic study of the way in which torture works to extinguish the building blocks of rational thought. Much of what she writes about the effects of manmade pain on the psyche is applicable to natural pain as well.

'Physical pain always mimes death' says Scarry (p. 31). For pain turns the sufferer's attention to an ever existing possibility for ending it: death. Death has a way of 'announcing itself in suffering', and thus foreshadow the ultimate extinction of knowledge and experience. ${ }^{26}$ But in contrast with the total negation which is death, pain implies two specific losses: that of the unity between body and psyche, and that of words.

Pain dismantles the unity between body and soul when the body of the sufferer becomes the tool with which extreme anguish is brought about. The horrific experience of one's own body turning into an enemy is exceptionally salient in torture. But people with very painful illness also feel a sharp sense of betrayal on the part of their body. This is an effect that is unique to pain, but it is best described in terms of destruction and loss. And so, the evil of pain can only be understood on a background of the good - the integrity of body and soul - of which it is a privation.

A different, and perhaps deeper loss wrought by pain is that of the logos. Great physical pain tends to efface the content of consciousness.

${ }^{26}$ See also Lévinas and Hand, p. 40. See also Améry on 'the equation Body $=$ Pain $=$ Death' (p. 34). 
In the depth of misery, physical pain erases all the subjects of human cognizance, leaving only the consciousness of the aching body: 'Frail in the face of violence, yelling out in pain, awaiting no help... the tortured person is only a body, and nothing else besides that. ${ }^{27}$ The destruction of consciousness wrecked by pain is most powerfully manifested in the gradual annihilation of language. First, pain becomes the dominant subject of language, as complaint takes over other forms of speech. But then (or if the pain is overwhelming, right at the start) coherent sentences and words give way to pre-lingual groans and cries.

Pain itself is stubbornly resistant to verbal expression, ${ }^{28}$ and when it takes hold of the entire space of consciousness it drives language away and the sufferer regresses to a pre-lingual stage. As language collapses under the immense pressure of pain so does the entire complex content of the mature psyche. When the victim 'sees stars' she cannot see her loved ones, the political ideals in which she believed, the places she belongs to or the personal history that gives meaning and context to her life. ${ }^{29}$ From the point of view of its effects pain is therefore a powerful expression of the privation thesis, as it comes down to a loss of reason and humanity.

\section{CONCLUSION}

This paper set out to explore the hunch that pain is an 'evil in the flesh' and is therefore a 'real bad' that refutes the privation analysis of evil. It turns out that this intuition cannot survive a conceptual analysis that takes into account the findings of modern science. For these show us that the two components of the phenomenon of pain, the somatic and the affective, are separate not only analytically but also physically and psychologically. And so, while the anguish of pain is indeed generally thought to be bad, those features of pain that make people think that it is too real to be privative are rooted in the bodily sensation of pain. But pain as a bodily sensation is not bad at all, it is essential for the proper functioning of the

\footnotetext{
${ }^{27}$ Améry, p. 33; see also Korsgaard, p. 153, and Swenson, p. 208.

${ }^{28}$ As Virginia Woolf noted: 'English which can express the thoughts of Hamlet and the tragedy of Lear has no words for the shiver or the headache.' V. Woolf, On Being Ill (Ashfield, Mass.: Paris Press, 2002).

${ }^{29}$ This is why the 'betrayal' under torture is nothing of the kind - one cannot betray what one cannot possibly feel loyal to. The purpose of the interrogation that always accompanies torture is first and foremost the affirmation of the world-destroying effect of pain, and thus of the absolute power of the regime (Scarry, pp. 29-38).
} 
creature in which it occurs. The realness of pain and its negative value thus belong with different independent aspects of it.

The objectors are left with two other aspects of pain that can potentially refute the privation thesis: the condition of suffering, and pain's effect on the painful body and limb. But even if the badness of these aspects of pain is left undisputed, both these aspects are best described in negative terms of avoidance and lack: painfulness is a condition you want to put an end to, run away from, stop. The effects of pain are similarly rendered in privative terms, as a change that is essentially a destruction: of the body-soul integrity, and of the consciousness of anything besides the pain. Looked at from that angle, pain is actually a good example an analysis of evil in terms of privation. For as argued by Augustine, what is real in pain, i.e. its embodiment, is not the source of its negative value, and what is bad in pain is best understood as escape, loss and lack. ${ }^{30}$

\section{BIBLIOGRAPHY}

Adams, Robert Merrihew. Finite and Infinite Goods: A Framework for Ethics (New York: Oxford University Press, 1999)

Aertsen, Jan. Medieval Philosophy and the Transcendentals: The Case of Thomas Aquinas (Bd. 52, Brill, Leiden: Studien und Texte zur Geistesgeschichte des Mittelalters, 1996)

Améry, Jean. At The Mind's Limits: Contemplations by a Survivor on Auschwitz and its Realities (Bloomington: Indiana University Press, 1980)

Aquinas, Thomas. Summa Theologiae (London: Burns, Oates, and Washbourne, 1912-36)

Augustine. 'On the Nature of Good' in P. Schaff, ed. Nicene and Post-Nicene Fathers (Buffalo, NY: Christian Literature Publishing Co., 1887)

Augustine. 'On the Nature of the Good' in P. Schaff, ed. A Select Library of Nicene and post-Nicene Fathers of the Christian Church: A New Series (Oxford, Buffalo: Parker \& Co., The Christian Literature Company, 1886)

Calder, Todd. 'Is the privation theory of evil dead?', American Philosophical Quarterly, 44 (2007), 371

Hardcastle, Valerie Gray. 'When Pain is Not', The Journal of Philosophy, 94 (1997), 381 Horn, Sandra \& Marcus Munafò. Pain: Theory, Research, and Intervention (Buckingham: Health Psychology, Open University Press, 1997)

Kane, G. Stanley. 'Evil and Privation', Int J Phil Rel, 11 (1980), 43

\footnotetext{
${ }^{30}$ I am grateful to Bill Edmundson, Moshe Halbertal, Dennis Patterson and Christian Schemmel and Leif Wenar for their helpful comments, and to the EUI in Florence for a generous Max Weber fellowship.
} 
Korsgaard, Christine Marion. The Sources of Normativity (Cambridge: Cambridge University Press, 1996)

Kretzman, Norman \& Eleonore Stump. 'Being and Goodness' in S. MacDonald, ed. Being and Goodness: The Concept of the Good in Metaphysics and Philosophical Theology (Ithaca: Cornell University Press, 1991)

Lévinas, Emmanuel \& Sean Hand. The Levinas Reader (Oxford: Blackwell, 1989) Melzack, Ronald. The Puzzle of Pain (New York: Basic Books, 1973)

Nagel, Thomas. The View From Nowhere (New York: Oxford University Press, 1986) Ophir, Adi. Speaking Evil: Towards an Ontology of Morals (Tel-Aviv: Am Oved \& Van Leer institute, 2000)

Ricœur, Paul. The Symbolism of Evil (Boston: Beacon paperback Ariadne, Beacon Press, 1969)

Scarry, Elaine. The Body in Pain: The Making and Unmaking of the World (New York: Oxford University Press, 1985)

Sufka, Kenneth. 'Sensations and Pain Processes', Philosophical Psychology, 13 (2000), 299

Swenson, Adam. 'Pain's Evils', Utilitas, 21 (2009), 197

Woolf, Virginia. On Being Ill (Ashfield, Mass.: Paris Press, 2002) 